\title{
Proceeding
}

Supplementary Issue: Autumn Conferences of Sports Science. Costa Blanca Sports Science Events, 18-19 December 2020. Alicante, Spain.

\section{Weight bearing aerobic exercises versus whole body vibration on bone mineral density post thyroidectomy}

\author{
SHAIMAA MOHAMED ELSAYEH ${ }^{1} \triangle$, NORAN AHMED ELBEHERY², ZEINAB A. ALI ${ }^{1}$ \\ ${ }^{1}$ Department of Physical Therapy for Surgery, Faculty of Physical Therapy, Cairo University, Giza, Egypt \\ ${ }^{2}$ Department of Basic Science, Faculty of Physical Therapy, Cairo University, Giza, Egypt
}

\begin{abstract}
One of the health problems occurring post thyroidectomy is osteoporosis which has a greater impact on the patients' lives as it affects the strength and quality of bone and increases the fracture risk. This study was conducted to identify the beneficial therapeutic effect of weight bearing aerobic exercises and whole-body vibration training on bone mineral density post thyroidectomy and also to compare between their effects. In this study, forty-five patients of both sexes underwent thyroidectomy and had osteoporosis were included. Fifteen patients performed weight bearing aerobic exercises in addition to their routine medications and fifteen patients were trained on whole body vibration in addition to their routine medications, while remaining fifteen cases received only their routine medications. Dual Energy X-ray Absorptiometry (DEXA) is used to evaluate the bone mineral density before and after six months of treatment ( 28 weeks) for all groups. The mean values of BMD of lumbar spine and neck of femur in all groups were significantly increased. The percentages of bone mineral density improvement for lumbar spine and femoral neck in the weight bearing exercise group were $18.63 \%$ and $19.82 \%$, in the whole-body vibration group were $22.17 \%$ and $29.82 \%$, while in the control group were $7.47 \%$ and $3.63 \%$. So, it can be concluded that the weight bearing aerobic exercises and WBV training have a therapeutic beneficial effect on improving the bone mineral density in patient underwent thyroidectomy, but the whole-body vibration was more effective than weight bearing aerobic exercises.
\end{abstract}

Keywords: Weight bearing aerobic exercise; Bone mineral density; Whole body vibration; Osteoporosis; Thyroidectomy.

\section{Cite this article as:}

Elsayeh, S.M., Elbehery, N.A., \& Ali, Z.A. (2021). Weight bearing aerobic exercises versus whole body vibration on bone mineral density post thyroidectomy. Journal of Human Sport and Exercise, 16(2proc), S404-S409. doi:https://doi.org/10.14198/jhse.2021.16.Proc2.25

Corresponding author. Department of Physical Therapy for Surgery, Faculty of Physical Therapy, Cairo University, Giza, Egypt. E-mail: yhusseinabbas@yahoo.com

Abstract submitted to: Autumn Conferences of Sports Science. Costa Blanca Sports Science Events, 18-19 December 2020. Alicante, Spain.

JOURNAL OF HUMAN SPORT \& EXERCISE ISSN 1988-5202

(c) Faculty of Education. University of Alicante

doi:10.14198/jhse.2021.16.Proc2.25 


\section{INTRODUCTION}

The skeletal system is undergoing in continuous processes of bone modelling and remodelling to maintain its dynamic characteristic. There are two key players of bone remodelling: osteoblasts (for bone resorption) and osteoclasts (for bone formation). Osteocytes (acting as mechanosensor and derived from osteoblasts) and the bone lining cells are also involved in the remodelling process (Katsimbri, 2017; Vlasova, 2020).

The bone remodelling process is important as it is responsible for micro-fractures repair, prevention of fragile bones formation and to balance the homeostasis between calcium and phosphate (Kenkre \& Bassett, 2018; de Lima 2018).

The development of the skeletal system and its maintenance in good state depend on many factors; genetic factors, sufficient metabolic and hormonal functions, ample mechanical load (exercises) and balanced diet. Severe consequences will occur if there is any imbalance among these factors as osteoporosis (excessive bone resorption) and osteopetrosis (excessive bone formation) (Tuchendler \& Bolanowski, 2014; Misse, 2018).

Thyroid hormone has important role in bone turnover by increasing the activation of new cycles of remodelling and stimulating the activity of osteoplastic and osteoclastic in cortical and trabecular bone. After total or partial thyroidectomy and radioiodine therapy, calcitonin secretion is dramatically reduced leading to osteopenia due to deregulation of bone resorption. Also excess endogenous thyroxin and over enthusiastic thyroid replacement therapy following thyroidectomy led to osteoporosis (Dhanwal, 2011; Nikolaou \& Markogiannakis, 2017).

Osteoporosis is increasing fracture risk as it affects the bone strength and quality through substantial bone mass loss and bone tissue micro-architecture deterioration. Fractures cause chronic pain, functional capacity loss and decreased life quality (Linda et al., 2014).

Bone is a dynamic tissue that responds to different stimuli like physical exercises and mechanical vibrations. The bone mass is maintained or gained by muscles contractions exerted on bones and by the mechanical forces exerted through ground reaction forces (Kelly et al., 2013).

In weight-bearing aerobic exercises such as walking, jogging, climbing, and jumping, the body works against gravity giving an osteogenic stimulus that enhance bone mass compared with non-weight bearing aerobic exercises such as swimming, water aerobics and cycling that usually accompanied with a decreased bone mineral density (Nikander et al., 2009).

The vibrating platforms in whole body vibration (WBV) produces sinusoidal oscillations in vertical or rotational mode that transmitted to the entire body. It has been reported that whole body vibration improves muscular performance, increases muscle power and strength, improves body balance, and increase bone formation (Kawashima et al., 2007).

\section{MATERIALS AND METHODS}

This Stochastic and with control research, which intended to evaluate the therapeutic advantages of weight bearing aerobic phenomena and body shake on bone mineral density post thyroidectomy and compare 
between them. The patients were chosen of Kasr Al Ainy Teaching Hospital, Cairo University in Egypt and the study carried out during the period of March 2018 to November 2019.

Group A (weight bearing aerobic exercises), group B (whole body vibration "WBV") and group C (control group). All subjects in all groups received their routine medical intervention.

\section{RESULTS}

\section{Subject characteristics}

The characteristics of subjects in group A, B and C showed in Table (1). Regarding the age and BMI, no significant difference was formulated among any groups $(p>.05)$. Also, no significant difference was founded between groups in sex distribution $(p>.05)$.

Table 1. Basic characteristics of participants.

\begin{tabular}{lcccc}
\hline & Group A & Group B & Group C & \multirow{2}{*}{-value } \\
\cline { 2 - 4 } & Mean \pm SD & Mean \pm SD & Mean \pm SD & \\
\hline Age (years) & $32.53 \pm 5.61$ & $31.8 \pm 4.58$ & $33.06 \pm 4.46$ & .77 \\
BMI $\left(\mathrm{kg} / \mathrm{m}^{2}\right)$ & $26.38 \pm 2.01$ & $26.83 \pm 2.36$ & $26.23 \pm 2.17$ & .73 \\
Sex $\mathrm{n}(\%)$ & & & & \\
Females & $9(60 \%)$ & $10(67 \%)$ & $8(53 \%)$ & \multirow{2}{*}{.75} \\
Males & $6(40 \%)$ & $5(33 \%)$ & $7(47 \%)$ & \\
\hline
\end{tabular}

\section{Within group comparison}

Within group comparison of pre- and post-treatment BMD, the BMD of lumbar spine and neck of femur was significantly increased in group $A(p<.001)$, group $B(p<.001)$ and group $C(p<.01)$. (Table 2$)$ and (Figure 1).

\section{Between group comparison}

Between group comparison pre-treatment revealed a non-significant difference between groups ( $p>.05)$. While between groups post-treatment comparison revealed that there was a significant increase in lumbar spine and neck of femur bone mineral density of group B compared with that of group $A(p<.05)$ and that of group $C(p<.001)$. Also, bone mineral density of lumbar spine and neck of femur of group $A$ was significantly increased when compared with that of group C post-treatment $(p<.01)$. (Table 3$)$.

Table 2. Mean lumbar spine and neck of femur BMD pre- and post-treatment of all groups: $A, B$ and $C$.

\begin{tabular}{lccc}
\hline & Group A & Group B & Group C \\
\cline { 2 - 4 } & Mean \pm SD & Mean \pm SD & Mean \pm SD \\
\hline Lumbar spine & $-2.2 \pm 0.19$ & $-2.12 \pm 0.18$ & $-2.14 \pm 0.17$ \\
Before treatment & $-1.79 \pm 0.16$ & $-1.63 \pm 0.17$ & $-1.98 \pm 0.15$ \\
After treatment & $-0.41(-0.49:-0.31)$ & $-0.49(-0.58:-0.4)$ & $-0.16(-0.24:-0.07)$ \\
MD (95\% Cl) & $p=.001$ & $p=.001$ & $p=.001$ \\
\hline Femoral neck & $-2.32 \pm 0.23$ & $-2.28 \pm 0.22$ & $-2.2 \pm 0.27$ \\
Before treatment & $-1.86 \pm 0.24$ & $-1.6 \pm 0.2$ & $-2.12 \pm 0.28$ \\
After treatment & $-0.46(-0.52:-0.39)$ & $-0.68(-0.74:-0.61)$ & $-0.08(-0.15:-0.02)$ \\
MD (95\% Cl) & $p=.001$ & $p=.001$ & $p=.01$ \\
\hline S406 | 2021|Proc2 | VOLUME 16 & & ○ 2021 University of Alicante
\end{tabular}


Table 3. Comparison of mean lumbar spine and neck of femur BMD post-treatment between groups; A, B and $\mathrm{C}$.

\begin{tabular}{lccc}
\hline & Group A vs. group B & Group A vs. group C & Group B vs. group C \\
\hline Lumbar spine & & & \\
MD $(95 \% \mathrm{Cl})$ & $-0.16(-0.3:-0.01)$ & $0.19(0.03: 0.33)$ & $0.35(0.19: 0.49)$ \\
& $p=.03$ & $p=.009$ & $p=.001$ \\
\hline $\begin{array}{l}\text { Femoral neck } \\
\text { MD }(95 \% \mathrm{Cl})\end{array}$ & $\begin{array}{c}-0.26(-0.47:-0.03) \\
p=.02\end{array}$ & $\begin{array}{c}0.26(0.03: 0.48) \\
p=.01\end{array}$ & $\begin{array}{c}0.52(0.29: 0.73) \\
p=.001\end{array}$ \\
\hline
\end{tabular}

\section{DISCUSSION}

Patients who underwent thyroidectomy totally or partially had a higher risk of osteoporosis about 1.43 times when compared with the patients who did not underwent thyroidectomy. The risk of post thyroidectomy osteoporosis is higher in women, subjects younger than 50 years old, and patients having comorbidities (Chien-Ling et al., 2018).

It was founded in this study that both of weight bearing aerobic exercises and WBV are effective in BMD improvement in patients underwent thyroidectomy.

The weight bearing aerobic exercises create an intermittent mechanical stress on the skeletal system and stimulate the mesenchymal stem cells, the activity of osteoblast and osteocyte and osteogenic differentiation, all of that improve bone strength and induce bone formation. The changes in hormones levels such as the parathyroid hormone (PTH), oestrogen and prostaglandin E2 occurring in aerobic exercises also increase bone formation and osteogenic differentiation (Yuan et al., 2016).

But in this study the WBV was more effective in improving bone mineral density when compared to weight bearing aerobic exercises. This result could be as WBV acts on two mechanisms: direct and indirect.

The direct mechanism of WBV to produce osteogenic effects may be due to changes in the flow of bone fluid through mechano-transduction and bone stimulation (Judex and Rubin, 2010). Also, it is assumed that the vibration causes micro-trauma to the bone which is repaired by osteoblast cells latterly (Turner et al., 1995).

Whole body vibration indirectly stimulates bone through increasing the neuromuscular training and activation of skeletal muscle as the muscle contract and relax by neural reflex about 7-28 times per second while once or twice per second in conventional exercises. Also, WBV results in involuntary muscle contractions and approximately 97 percent of muscle-fibres is engaged while only 45 percent of muscle fibres is engaged in conventional exercises (Kawanabe et al., 2007). Both of the ground reaction and the strain forces caused by these various types of muscle contractions generate proper mechanical stresses that increase bone formation and strength, increase BMD, and prevent development of osteoporosis (Yuan et al., 2016).

WBV training is also increasing testosterone and growth hormones levels which indirectly affecting bone remodelling (endocrine system response) (Bosco et al., 2000). 


\section{CONCLUSION}

In conclusion, it can be founded that the significant enhancement in BMD in this study proved the effectiveness of weight bearing aerobic exercises and WBV strongly and the better results were in favour to all body vibration training.

\section{REFERENCES}

Bosco, C., lacovelli, M., Tsarpela, O., Cardinale, M., \& Bonifazi, M. (2000). Hormonal responses to wholebody vibration in men. Eur J Appl Physiol., 81, 449-454. https://doi.org/10.1007/s004210050067

Chien, M.Y., Wu, Y.T., Hsu, A.T., Yang, R.S. \& Lai, J.S. (2000). Efficacy of a 24-week aerobic exercise program for osteopenic postmenopausal women. Calcif Tissue Int., 67(6), 443- 448. https://doi.org/10.1007/s002230001180

Chien-Ling, H., Chih-Ching, Y., Pi-Shan, S., Chung-Jye, H., Chih-Hsin, M., Fung-Chang, S., I- Ming, J., \& Kuen-Jer, T. (2018). Is partial or total thyroidectomy associated with risk of longterm osteoporosis: a nationwide population-based study. World J Surg., 42, 2864-2871. https://doi.org/10.1007/s00268018-4573-2

de Lima, R. S. (2018). Violence and public safety as a democratic simulacrum in Brazil. International Journal of Criminology and Sociology, 7, 159-172. https://doi.org/10.6000/1929-4409.2018.07.11

Dhanwal, DK. (2011). Thyroid disorders and bone mineral metabolism. Indian J Endocrinol Metab., 15(I2), 107-112. https://doi.org/10.4103/2230-8210.83339

Gianna, C.L., Todd, C.S., \& Hawley, C.A. (2012). Whole body vibration training is osteogenic at the spine in college-age men and women. J Hum Kinet., 31, 55-68. https://doi.org/10.2478/v10078-012-00068

Hawley, C.A. (2017). Whole body vibration training attenuates bone loss in osteoporosis: a case report. Almstedt, J Osteopor Phys Act, 5(1), 196.

Judex, S. \& Rubin. C.T. (2010). Is bone formation induced by high frequency mechanical signals modulated by muscle activity? J Musculoskelet Neuronal Interact., 10(1), 3-11.

Katsimbri, P. (2017). The biology of normal bone remodeling. European Journal of Cancer Care, 26, e12740. https://doi.org/10.1111/ecc.12740

Kawanabe, K., Kawashima, A., Sashimoto, I., Takeda, T., Sato, Y. \& Iwamoto, J. (2007). Effect of whole body vibration exercise and muscle strengthening, balance and walking exercises on walking ability in the elderly. Keio J Med., 56, 28-33. https://doi.org/10.2302/kjm.56.28

Kawashima, A., Sashimoto, I., Takeda, T., Sato, Y. \& Iwamoto, J. (2007). Effect of whole body vibration exercise and muscle strengthening, balance and walking exercises on walking ability in the elderly. Keio J Med., 56, 28-33. https://doi.org/10.2302/kjm.56.28

Kelley, G.A., Kelley, K.S. \& Kohrt, W.M. (2013). Exercise and bone mineral density in premenopausal women: a meta-analysis of randomized controlled trials. Int J Endocrinol. 741639. https://doi.org/10.1155/2013/741639

Kenkre, J.S. \& Bassett, J. (2018). The bone remodeling cycle. Annals of Clinical Biochemistry, 55, 308327. https://doi.org/10.1177/0004563218759371

Linda, D.F. Moreira1, M.L., Ana P.L., Rosângela, V.M., Rodrigo, N.d. \& Marise, L.C. (2014). Physical exercise and osteoporosis: effects of different types of exercises on bone and physical function of postmenopausal women. Arq Bras Endocrinol Metab. 58(5), 514- 522. https://doi.org/10.1590/0004$\underline{2730000003374}$ 
Misse, M. (2018). Violence, criminal subjection and political merchandise in Brazil: an overview from Rio. International Journal of Criminology and Sociology, 7, 135-148. https://doi.org/10.6000/19294409.2018.07.09

Nikolaou, E., \& Markogiannakis, G. (2017). Greek preschool teachers' perceptions about the effective strategies for bullying prevention in preschool age. International journal of criminology and sociology, 6, 172-177. https://doi.org/10.6000/1929-4409.2017.06.18

Nikander, R., Kannus, P., Dastidar, P., Hannula, M., Harrison, L., Cervinka, T., Narra, N., Aktour, R., Arola, T., Eskola, H., Soimakallio, S., Heinonen, A., Hyttinen, J. \& Sievänen, H. ( 2009). Targeted exercises against hip fragility. Osteoporos Int., 20(8), 1321-8. https://doi.org/10.1007/s00198-008$\underline{0785-x}$

Totosy de Zepetnek, J.O., Giangregorio, L.M. \& Craven, B.C. (2009). Whole-body vibration as a potential intervention for people with low bone mineral density and osteoporosis: A review. J Rehabil Res Dev., 46, 529-542. https://doi.org/10.1682/JRRD.2008.09.0136

Tuchendler, D. \& Bolanowski, M. (2014). The influence of thyroid dysfunction on bone metabolism. Thyroid Research., 7(1), 12. https://doi.org/10.1186/s13044-014-0012-0

Turner, C.H., Takano, Y. \& Owan, I. (1995). Aging changes mechanical loading thresholds for bone formation in rats. J Bone Miner Res.,10(10), 1544-1549. https://doi.org/10.1002/jbmr.5650101016

Vlasova, N. (2020). Comical as a way of reflecting political daily occurrence In A. Platonov's novel "Tchevengur". Journal of Social Sciences and Humanities Research, 8(2).

Yuan, Y., Chen, X., Zhang, L., Wu, J., Guo, J., Zou, D. \& Zou, J. (2016). The roles of exercise in bone remodeling and in prevention and treatment of osteoporosis. Prog Biophys Mol Biol., 122(2), 12230. https://doi.org/10.1016/j.pbiomolbio.2015.11.005

\section{(@) $(\Theta \Theta \Theta$}

This work is licensed under a Attribution-NonCommercial-NoDerivatives 4.0 International (CC BY-NC-ND 4.0). 